\title{
Book review: Lithic Materials and Paleolithic Societies
}

\author{
Christopher D. Noll
}

Versar, Inc., 5918 W. Victory Rd., Boise, Idaho, USA. Email: cnoll77@gmail.com

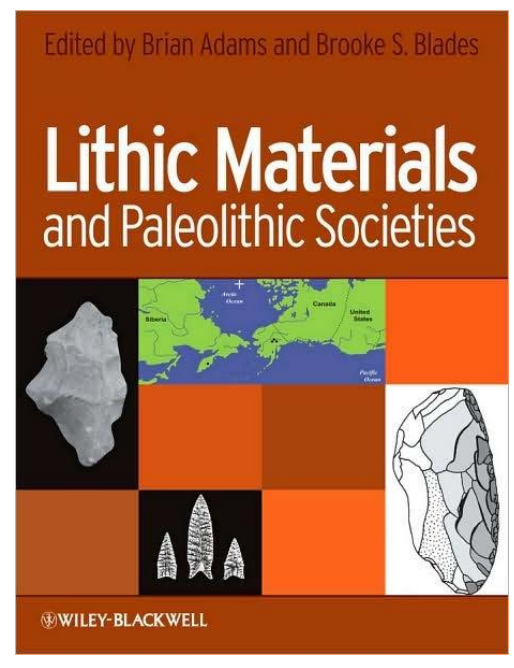

Lithic Materials and Paleolithic Societies

Edited by Brian Adams and Brooke S. Blades

Blackwell Publishing Ltd., 2009, pp. 304. ISBN 978-1-405-16837-3

Publisher's website: doi:10.1002/9781444311976

Lithic Materials and Paleolithic Societies is an edited volume of research papers that provides perspectives on the study of lithic technological organization from around the world. The book contains 20 chapters organized into four thematic sections focused on stone procurement, tool-stone use, the role of tool-stone subsistence and settlement systems, and the clues about social interaction that are gleaned from the study of lithic materials.

Chapter 1 examines decisions made by some of the earliest toolmakers regarding toolstone procurement and use. Evidence suggests that the properties of high-quality knappable stone were being selected for as early as 2.3 million years ago. Chapter 2 provides a detailed overview of the variability of Middle Paleolithic provisioning and toolkit organization. Chapter 3 considers the implications of long-distance tool-stone transfers at Upper and Middle Paleolithic sites in Western Europe. The study recognizes differences between periods tied to socioeconomic conditions of the periods. Chapter 4 is a Central European case study regarding the advancements in tool-stone provenance studies with special emphasis on the

Published by the School of History, Classics and Archaeology, University of Edinburgh ISSN: 2055-0472. URL: http://journals.ed.ac.uk/lithicstudies/

This work is licensed under a Creative Commons Attribution 2.5 UK: Scotland License. 
value of cooperative research and data sharing. Chapter 5 compares microblade and nonmicroblade assemblages from sites in the Bering Sea region to examine the ways microblade assemblages reflect distinct behavioral patterns and planning, where non-microblade sites do not. Chapter 6 is an analysis of assemblages in Arnhem Land, Australia that identifies the factors which influence variation within assemblages. The study recognizes the assemblages as dynamic, rather than static components related to a single group and period. Variation is viewed as a result of decision making processes related to stone procurement, tasks, and the associated costs of alternative responses that are active many times at sites.

Chapter 7 is an investigation of Pleistocene hominin preferences and behavior associated with morphologically differentiated tool-stone types. The chapter identifies correlations between raw material characteristics, technology, adaptive strategy, and site selection. Chapter 8 presents an overview of research related to the Gravettian period in Hungary. The author demonstrates variability of tool-stone use within the period. Chapter 9 examines the differences between local and non-local tool-stone in three French Paleolithic assemblages as a function of blank portability and distance attrition. Chapter 10 explores the debitage associated with Paleoarchaic sites in the Great Basin of western North America to test the idea that biface reduction during the period is a product of a single reduction sequence approach during the period with stages of reduction distributed across multiple sites. Transport cost is viewed as a determining factor of reduction behavior.

Chapter 11 is a case study of a Lower Paleolithic site in Nambia. The analysis shows the site is a palimpsest of short, non-domestic reduction episodes. The author provides a discussion of the theoretical implications of this tool production pattern. Chapter 12 provides another case study; the chapter looks at a Lower and Middle Paleolithic quarry in Israel. The site provides an example from the periods that demonstrates the sophistication of intensive tool production and situational awareness reflected in land-use practices. Chapter 13 explores the relationship between tool-stone procurement and subsistence fauna at a Paleolithic rockshelter in France. The pattern of core reduction and faunal species represented is used to infer the nature of movement near the site. Chapter 14 examines the utilization of discrete raw material sources in the mountains of southern Poland during the Middle and Late Paleolithic. Much of the use of the material is associated with hunting activities but the artifacts of one level of the study site are noted to strongly suggest symbolic or ritual behavior. Chapter 15 examines the pattern of raw material use and core reduction strategies over time at an Upper Paleolithic site in France. The patterns reveal changes in the land-use pattern over time.

Chapter 16 is a detailed study of Acheulean bifaces from 10 sites on the Deccan Plateau of India. The analysis determined that tool making was learned by imitation, and two distinct tool types were made in anticipation of specific applications. Chapter 17 analyses the organization of Quina Mousterian lithic technology. The system is shown to be a highly flexible material package and core reduction system that reflects Neanderthal planning for specific needs. Chapter 18 reconsiders the notion that Szeletian assemblages are a product of interaction between Neanderthals and anatomically modern humans. The influence of raw material quality on the composition of lithic assemblages is explored. Chapter 19 examines the factors influencing tool retouch intensity at Paleolithic sites in the Transbaikal region of Siberia. Retouch and raw material selection are shown to be strongly correlated with tool function. Chapter 20 analyzes the patterns of lithic tool-stone procurement at Clovis and Dalton sites. The analysis demonstrates distinct differences in stone procurement between the two cultures indicating that Dalton is not a continuation of earlier Paleoindian lifeways.

Lithic Materials and Paleolithic Societies is a thought provoking collection of theorydriven research related to the lithic technological organization of early tool makers. The contributions from scholars around the world provide valuable diversity in the scales and perspectives of research. This volume is a worthwhile reference for lithic analysts. 